\title{
Incidence of perforated duodenal and gastric ulcer in Oxford
}

\author{
ROGER SANDERS \\ From the Department of Radiology, The Radcliffe Infirmary, Oxford
}

EDITORIAL COMMENT A detailed study of particular value for comparison with other centres, it provides further evidence of the falling incidence of duodenal ulcer in Great Britain. In and around Oxford the incidence of perforated peptic ulcer was 14/100,000 in 1957 and in 1963 it was $7 / 100,000$, the fall being due to duodenal and not to gastric ulcer.

The population incidence of perforated gastric and duodenal ulcer has been the subject of several studies (Illingworth, Scott, and Jamieson, 1944; Jamieson, 1955; Pulvertaft, 1959; Weir, 1960). Although some concerned 'peptic ulcer' incidence it is clear that gastric and duodenal ulcer perforation rates should be considered separately because the incidence of the two lesions differs (Jennings, 1940; Truelove and Reynell, 1963).

In an area with reasonable medical care it is probable that all cases of perforated peptic ulcer will reach hospital, and the diagnosis be confirmed either radiologically, at operation, or at necropsy. Statistics from hospitals in different areas providing a complete population coverage are likely to be comparable. Earlier surveys have shown that the incidence of duodenal ulcer and gastric ulcer has altered, and it has been suggested that epidemics of duodenal and gastric ulcers have just occurred in the British Isles (Susser and Stein, 1962). The purpose of this study was to discover whether the incidence in Oxford and the surrounding district reflected this change.

\section{DESIGN OF THE SURVEY}

The period surveyed was from 1 January 1957 to 31 December 1963. An area was taken similar to that used in the Oxford Record Linkage Study (Acheson, 1964) and consisted of Oxford County Borough and 12 surrounding urban and rural districts. The total population in this area on 31 December 1960 was 306,600 and this was assumed to be the average population throughout the period of the survey.

The hospital services for this population are provided almost exclusively by the group of teaching hospitals associated with Oxford which draws patients from a considerably wider area than that covered by the study. Surveys in association with the Oxford Record Linkage
Study have shown that not more than $5 \%$ of the total number of hospital admissions experienced by the population in the area occur in hospitals outside the area.

ASCERTAINMENT OF CASES The following methods of case findings were used:

1 The case notes of all patients living in the defined area filed on the teaching hospital group diagnostic index as perforated gastric ulcer (540.1) and perforated duodenal ulcer (541.1) between 1957 and 1963 were examined.

2 A search was made of the records of the local mental hospitals, of the only private nursing home in the area providing surgical facilities, and of the local geriatric hospital.

3 All necropsies in the Oxford area are performed at the Radcliffe Infirmary; the post-mortem diagnostic index was checked to exclude the possibility that perforation was not recognized during a patient's life-time. Five cases were unearthed in this fashion.

4 The diagnostic indices of two hospitals on the periphery of the area (the Horton General Hospital, Banbury, and the Royal Berkshire Hospital, Reading) were checked and 10 cases with addresses in the Oxford area were found and added to the survey. A third hospital (Tyndal Hospital, Aylesbury) on the periphery, which takes acute surgical cases, did not at the time of this survey possess a diagnostic index. It is therefore impossible to be certain that no cases living in the defined area had been sent there; however, other evidence suggests that no substantial loss to this hospital is likely.

Those cases in which there was surgical confirmation of a perforation, gas was present under the diaphragm radiologically, or a perforation had been found at necropsy were included in the study. Carcinomatous perforations and stomal ulcers were excluded. The ulcers were classified as gastric and pyloroduodenal; those described as 'pyloric' were placed in the latter category (Jamieson, 1955). The following information was then abstracted from the notes: name, address, age, sex, occupation, date of admission and discharge, site of 
ulcer, radiological appearance, type of operation performed, and if relevant, post-mortem findings.

\section{RESULTS}

Between 1957 and 1963 there were 221 cases of perforated peptic ulcer in the Oxford area. Of these, 177 were perforated duodenal ulcers, 41 were perforated gastric ulcers and in three there were both gastric and duodenal perforations. Generalized conditions incidentally involving the intestines (carcinoma of the jaw with metastases, subacute bacterial endocarditis with mesenteric infarction, overwhelming meningitis, and prostatectomy followed by mesenteric infarction) were the cause of death in four cases (gastric three, duodenal one) where incidental perforations were found. These cases have been excluded from all figures that follow.

AVERAGE ANNUAL INCIDENCE The annual average incidence of perforated peptic ulcer in Oxford and the surrounding area between 1957 and 1963 was $10 / 100,000 /$ year. The incidence of perforated duodenal ulcer was $8 / 100,000 /$ year and of perforated gastric ulcer $2 / 100,000 / y e a r$. These incidences are all low in comparison with the results of studies performed elsewhere in the British Isles (Table I). Table I shows that York and Aberdeen had a perforation incidence twice and three times respectively greater than that of Oxford in 1957.

The incidence of perforated duodenal ulcer in Great Britain has been falling since about 1950. In all surveys performed since then (Jamieson, 1955; Weir, 1960; Pulvertaft, 1959; Mackay, 1966) the incidence was greater at the beginning of the survey than at the end, and this survey is no exception (Table II). The incidence of perforated peptic ulcer in and around Oxford was $14 / 100,000$ in 1957; in 1963 it was $7 / 100,000$.

MEAN AGE The mean age of peptic perforation cases in the survey was 54, that of duodenal perforations was $51 \cdot 5$, and that of gastric perforations $61 \cdot 5$. The peptic perforation figure is higher than that in other surveys (Table III).

AGE-SPECIFIC INCIDENCE Figure I shows that the age-specific incidence for peptic ulcer in the Oxford area rose steeply up to age $40-49$ after which the gradient of increase became less steep. Earlier surveys have shown peak age-specific incidences ranging from $30-40$ to $40-50$ (Table IV).

DUODENAL ULCER/GASTRIC ULCER RATIO The ratio of duodenal ulcer to gastric ulcer was $4: 1$. This is a considerably lower ratio than that found in most

TABLE I

INCIDENCE OF PERFORATION PER 100,000 PER YEAR AND DUODENAL GASTRIC PERFORATION RATIO IN COMPARABLE SERIES

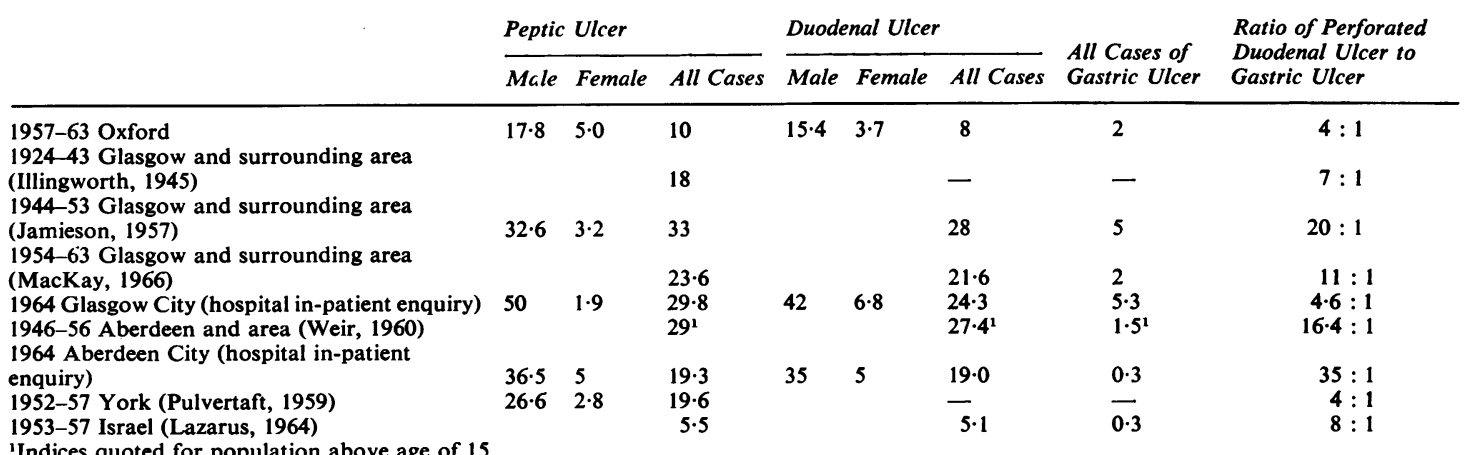

TABLE II

TOTAL NUMBER OF PERFORATIONS AND INCIDENCE BY YEAR IN OXFORD

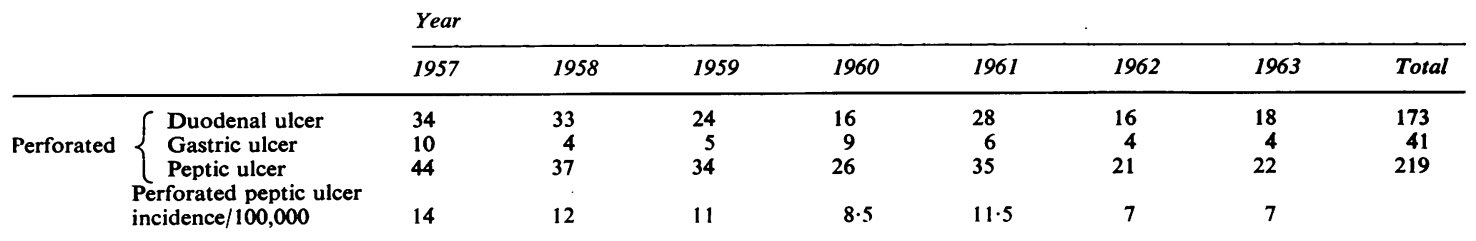


TABLE III

MEAN AGE AND PEAK AGE-SPECIFIC INCIDENCE OF PERFORATIONS IN COMPARABLE SERIES

\begin{tabular}{|c|c|c|c|}
\hline Peptic & Ulcer & Duode & enal Ulcer \\
\hline $\begin{array}{l}\text { Mean } \\
\text { Age }\end{array}$ & $\begin{array}{l}\text { Peak Age- } \\
\text { specific } \\
\text { Incidence }\end{array}$ & $\begin{array}{l}\text { Mean } \\
\text { Age }\end{array}$ & $\begin{array}{l}\text { Peak Age- } \\
\text { specific } \\
\text { Incidence }\end{array}$ \\
\hline
\end{tabular}

Glasgow (1924-43)

Glasgow (1944-53) (Jamieson,

1956)

1966)

Glasgow City (1964) (hospital

in-patient enquiry)

Aberdeen (1946-56) (Weir,

1960)

Aberdeen City (1964) (hospita

in-patient enquiry)

York (1952-57) (Pulvertaft,

1959)

Oxford (1957-63)

$\begin{array}{cccc}40 \cdot 9 & 30-39 & - & - \\ 42 & 40-49 & - & - \\ 47 & 50-54 & - & - \\ 49 & 55-64 & 44 & 55-64 \\ 46 & 45-54 & - & - \\ 52 & (45-54) & & \\ -55-74) & 52 & 45-54 \\ 54 & 45-54 & - & - \\ & 50-59 & 51 & 40-49\end{array}$

TABLE IV

MALE-FEMALE RATIOS IN COMPARABLE SERIES OF PERFORATIONS

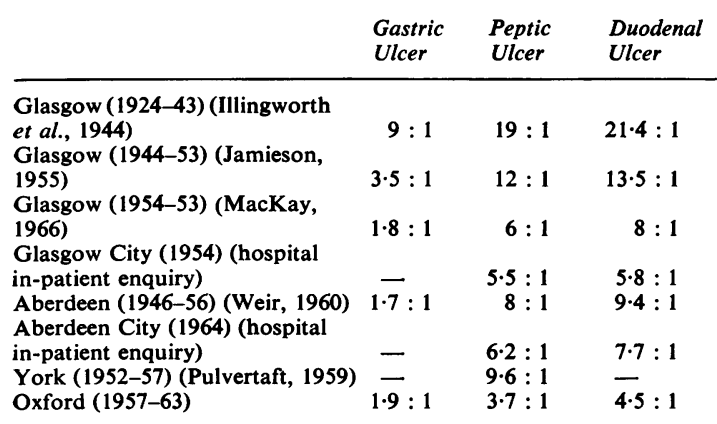

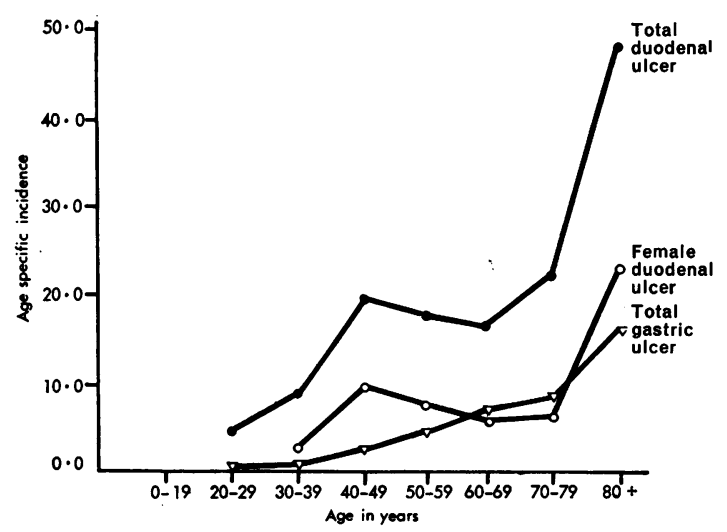

FIG. 1. Age-specific incidence/100,000/year for perforated duodenal ulcer and gastric ulcer in Oxford. previous surveys (Table I). Presumably this reflects a diminishing number of perforated duodenal ulcers, for the incidence of perforated gastric ulcers is relatively stationary.

SEX INCIDENCE There was a ratio of $5: 1$ between males and females in patients with perforated peptic ulcers. This ratio is low in comparison with previous surveys (Table IV). The ratio has steadily diminished since the original Glasgow survey (1924-43) when the very high figure of 19 males to 1 female was reached. The duodenal ulcer male-tofemale ratio showed a male preponderance even more obviously in the earlier years. There has been only a mild decline in the gastric ulcer male-tofemale ratio. The gastric ulcer perforation incidence has barely altered since the early survey (Table I). Therefore the high ratio of male to female perforated peptic ulcers between 1920 and 1940 was principally due to a rise in the number of male duodenal perforations, which is now declining.

All surveys so far performed have demonstrated that more males than females suffer from duodenal ulcers (Truelove and Reynell, 1963). This suggests that female sex hormones provide some protection against duodenal ulceration (Truelove, 1960). There is further evidence from this survey: the mean age of male perforated duodenal cases was $51 \cdot 5$ whereas that of female cases was 66, and there were only six (out of 32) pre-menopausal cases (Table V). On the

\section{TABLE V}

MALE AND FEMALE PERFORATION TOTALS AT OXFORD

\begin{tabular}{lclr} 
& Male & Female & Total \\
\hline Duodenal ulcer & $144(82 \%)$ & $32(18 \%)$ & 176 \\
Gastric ulcer & $26(65 \%)$ & $14(35 \%)$ & 40 \\
Peptic ulcer & $170(78.5 \%)$ & $46(21.5 \%)$ & 216
\end{tabular}

other hand the mean age of female gastric perforations was 59 and that of the male $61 \cdot 5$. The female sex is not protected against gastric ulceration; it is well known that gastric ulcers were common in women in the nineteenth century (Jennings, 1940) and since 1955 an epidemic of gastric ulcers has been taking place amongst young women in southern Australia (Billington, 1960a).

AVERAGE ANNUAL MORTALITY The average annual mortality rate in Oxford for perforated peptic ulcer was 1.9 per 100,000 , that for duodenal perforations was $1 \cdot 15$ per 100,000 , and for gastric perforations 0.75 per 100,000 . Thus although perforated gastric ulcer is a rarer disease than perforated duodenal ulcer it has almost as high a mortality rate. The British Isles as a whole has a mortality rate a little 
less than double these figures (Registrar General, $1960), 1.8$ and 1.3 respectively.

FATALITY RATE Amongst the 216 cases of peptic ulcer there were 43 deaths, a fatality rate of $20 \%$. This is a considerable increase on previous surveys (Table VI) and higher than the British hospital inpatient enquiry figures in 1957 (Johnson, 1962). A large proportion of these deaths was a consequence of the high gastric ulcer perforation death rate. In 40 cases there were 15 deaths $(37 \%)$, whereas in 173 cases of duodenal ulcer there were only 25 deaths $(14 \cdot 5 \%)$.

\section{TABLE VI}

FATALITY RATE IN COMPARABLE SERIES OF PERFORATIONS

\begin{tabular}{|c|c|c|c|}
\hline & \multicolumn{3}{|c|}{ Fatality Rate (\%) } \\
\hline & $\begin{array}{l}\text { Peptic } \\
\text { Ulcer }\end{array}$ & $\begin{array}{l}\text { Duodenal } \\
\text { Ulcer }\end{array}$ & $\begin{array}{l}\text { Gastric } \\
\text { Ulcer }\end{array}$ \\
\hline \multirow{6}{*}{$\begin{array}{l}\text { Glasgow (1924-43) (Illingworth, } \\
\text { 1945) } \\
\text { Glasgow (1944-53) (Jamieson, } \\
\text { 1957) } \\
\text { Glasgow City (1964) (hospital } \\
\text { in-patient enquiry) } \\
\text { Israel (1953-57) (Lazarus, 1964) } \\
\text { Aberdeen City (1964) (hospital } \\
\text { in-patient enquiry) } \\
\text { Oxford (1957-63) }\end{array}$} & 13 & - & - \\
\hline & $10 \cdot 1$ & 11 & 27 \\
\hline & $7 \cdot 5$ & $6 \cdot 3$ & - \\
\hline & $12 \cdot 2$ & - & - \\
\hline & 3.5 & 3.5 & $\overline{-}$ \\
\hline & 20 & $13 \cdot 8$ & $37 \cdot 5$ \\
\hline
\end{tabular}

It has been established that the fatality rate per cent increases markedly with age at perforation (Johnson, 1962; Weir, 1960) and the high mortality rate in this series is a reflection of the increasing age of patients who perforate (Table VII).

TABLE VII

MORTALITY FROM PERFORATED PEPTIC ULCER IN OXFORD

\begin{tabular}{lccccc} 
& $1957-59$ & & & $1960-63$ & \\
\cline { 2 - 3 } \cline { 5 - 6 } Age & Deaths & $\begin{array}{l}\text { Total } \\
\text { Cases }\end{array}$ & & Deaths & $\begin{array}{r}\text { Total } \\
\text { Cases }\end{array}$ \\
\hline $0-39$ & $0(0 \%)$ & 23 & & $0(0 \%)$ & 15 \\
$40-59$ & $9(18 \%)$ & 53 & & $2(9 \%)$ & 43 \\
$60+$ & $12(31 \%)$ & 38 & & $19(41 \%)$ & 46 \\
All & $21(18.3 \%)$ & 114 & $21(20.5 \%)$ & 104
\end{tabular}

There was a noticeably lower fatality rate at the beginning of the series in 1957 as compared with $1963: 8.5 \%$ to $17 \%$. In $1957,23 \%$ of patients with duodenal ulcer perforation were over the age of 60 ; by $196350 \%$ were over the age of 60 . In patients with perforated duodenal ulcer over the age of 70 there was a $45 \%$ fatality rate.
INFLUENCE OF STEROIDS Particular note was taken of cases treated with steroids; six cases were found $(2.6 \%)$. Of these four had perforated gastric ulcer $(8 \%)$ and two had perforated duodenal ulcer $(1 \%)$.

Three cases of perforated peptic ulcer cases treated with steroids died: one female (aged 45) gastric ulcer, reason for taking steroids unspecified; one male (aged 54) gastric ulcer, pemphigus; one female (aged 58) duodenal ulcer, regional enteritis.

Three cases of perforated peptic ulcer treated with steroids survived: one female (aged 49) gastric ulcer, multiple sclerosis; one male (aged 54) gastric ulcer, polyarteritis nodosa; one female (aged 63) duodenal ulcer, rheumatoid arthritis.

It is noticeable that the usual peptic ulcer sex ratio is reversed in this small series.

TYPE OF OPERATION The vast majority $(87 \%)$ of cases were oversewn. A more radical procedure was done in $4.5 \%$ (Table VIII).

TABLE VIII

TREATMENT OF PERFORATED PEPTIC ULCER AT OXFORD

\begin{tabular}{lc} 
Mode of Treatment & No. \\
\hline Oversewn & $189(87 \%)$ \\
Vagotomy and antrectomy & $1(0 \cdot 5 \%)$ \\
Limited gastrectomy & $1(0 \cdot 5 \%)$ \\
Polya operation & $4(2 \%)$ \\
Gastroenterostomy & $3(1.5 \%)$ \\
No operation & $18^{1}(8 \cdot 5 \%)$ \\
'Fourteen of these cases were moribund on arrival &
\end{tabular}

URBAN-RURAL DIFFERENCES IN INCIDENCE It is now well established that there is a difference in the incidence of peptic ulcer in town and country (Pulvertaft, 1959; Weir, 1960), which is confirmed in this study (Table IX).

\section{TABLE IX}

COMPARATIVE INCIDENCE OF PERFORATION IN URBAN AND RURAL DISTRICTS

\begin{tabular}{lcc} 
& $\begin{array}{c}\text { Number of } \\
\text { Cases }\end{array}$ & Incidence/100,000 \\
\hline Rural Oxfordshire & 81 & $7 \cdot 1$ \\
Oxford City and county boroughs & 135 & $14 \cdot 8$
\end{tabular}

\section{DISCUSSION}

Reliable population surveys of peptic ulcer and its complications have now been performed (Pulvertaft, 1959; Billington, 1960a; Billington, 1960b) and in each of these, perforations made up $11 \%$ of the chronic ulcer incidence. Perforation incidence faithfully reflected changes in chronic ulcer incidence (Billington, 1960b) so it seems possible to use 
perforation incidence as an indicator of total ulcer numbers.

The low incidence of perforated duodenal ulcer reported in this survey contrasts markedly with the incidence found 15 years ago in Aberdeen, Glasgow, and York (Table I). This might either be an artefact resulting from an inadequate search for perforation cases or a genuine difference of incidence in Oxford. It is unlikely that any cases were overlooked. At least two indices have been used in all years, and for 1962 the results were checked on three separate diagnostic indices: the teaching hospital index, the post-mortem diagnostic index, and the Oxford Record Linkage Study records. No discrepancy was found.

There is evidence to suggest that a somewhat lower incidence of duodenal ulcer might have been expected to occur in Oxford. A decrease in incidence of ulcer found at necropsy from the north to the south of the British Isles was noted in the national necropsy survey (Watkinson, 1958). The death rate from duodenal ulcer was higher in Scotland in 1955 $(12 / 100,000)$ than in England $(9 / 100,000)$ (Segi, Fujisaku, and Kurihara, 1959). A mortality atlas published recently shows a concentration of peptic ulcer deaths in Scotland whereas Oxford is in an area of low incidence (Howe, 1963).

The distribution of $\mathrm{ABO}$ blood groups in the British Isles is not uniform, and blood group $\mathrm{O}$, which is known to be associated with duodenal ulcer (Clarke, Pole Evans, McConnell, and Sheppard, 1959), is commoner in Scotland (Table X), particularly in Glasgow which has a large Irish element (Kopec, 1966). Perforated peptic ulcer figures for Glasgow and Aberdeen City residents were obtained for 1964 (Scottish Home Office); the perforation incidence is still considerably higher in these cities than in Oxford City (1962-63) (Table $\mathrm{XI})$. After a correction is made for the $\mathrm{ABO}$ incidence, which varies in the three cities, it will be seen that the difference in perforation incidence is diminished. Presumably the divergence in the incidence of peptic ulcer in the north and south of the British Isles is in part a consequence of the blood group distribution.

Although some of the difference. between earlier Scottish figures and the present survey is due to ABO blood group national variations, there is nevertheless considerable evidence to show that the British Isles has recently suffered an epidemic of duodenal ulcers affecting a limited cohort of men who are now growing aged (Susser and Stein, 1962). Between 1925 and 1950 perforated peptic ulcer increased in incidence (Illingworth et al., 1954; Jamieson, 1955; Weir, 1960; Pulvertaft, 1959), but since then a number of different surveys, including the present one, have registered a decline (Weir, 1960; Jamieson, 1955; Mackay, 1966) (Table I). The 1964 figures for Glasgow and Aberdeen cities, which are taken from the $100 \%$ Scottish Hospital In-patient Enquiry, confirm this trend (Table XI). The incidence for perforated peptic ulcer recorded in 1964 in Glasgow and Aberdeen was similar to that recorded for both the city and hinterland in the early 1950s (Jamieson, 1955; Weir, 1960) (Table I). However, it is known that the incidence

TABLE X

ABO BLOOD GROUP FIGURES ${ }^{1}$ FOR GLASGOW, OXFORD, YORK, AND ABERDEEN

Total No. of Cases Total No. of Cases in Each Blood Group

Glasgow

Aberdeen

York

Oxford, etc.

o

O

$\begin{array}{ll}4,967 & 3,078 \\ 2,115 & 1,438 \\ 2,566 & 2,23\end{array}$

$1,032 \quad 1,02$ 1,02

$A$
3,078
1,438
2,234
1,021

$\begin{array}{cc}B & A B \\ 1,017 & 295 \\ 450 & 153 \\ 485 & 202 \\ 187 & 76\end{array}$

Percentage of Cases in Each Blood Group

\begin{tabular}{llrl}
\hline$O$ & $A$ & \multicolumn{1}{l}{$\boldsymbol{B}$} & \multicolumn{1}{l}{$\boldsymbol{A} B$} \\
\hline 53.08 & 32.90 & 10.87 & 3.15 \\
50.89 & 34.60 & 10.83 & 3.68 \\
46.77 & 40.71 & 8.84 & 3.68 \\
44.56 & 44.08 & 8.07 & 3.28
\end{tabular}

TABLE XI

COMPARISON OF PERFORATED PEPTIC ULCER INCIDENCE IN 1964

\begin{tabular}{llll}
$\begin{array}{l}\text { Total No. } \\
\text { of Cases }\end{array}$ & $\begin{array}{l}\text { Incidence } \\
\text { Percentage Blood } \\
\text { Group } O\end{array}$ & $\begin{array}{l}\text { Group O(\%) } \\
\text { Incidence/100,000 }\end{array}$ \\
& 1100,000 & $\begin{array}{l}\text { Oxford } \\
\text { Group O(\%) } \\
\text { Respective } \\
\text { Scottish Towns }\end{array}$ \\
\hline
\end{tabular}

Glasgow City (1964) (Scottish Home and Health

Department)

Aberdeen City (1964) (Scoutish Home and Health

Department)

Oxford City (1964) (Oxford Record Linkage Survey)

307

36

19
$29 \cdot 8$

$19 \cdot 3$
18
53

51

$44 \cdot 5$
25

16.5 
in towns is approximately double that in the adjacent rural areas (Pulvertaft, 1959; Weir, 1960) so it seems reasonable to assume that the true incidence for areas comparable to those used in the earlier survey is now appreciably lower. The peak agespecific incidence for perforation has increased with each decade from 30-39 in 1930 to over 50 between 1957 and 1963 (Table III). The mean age of perforation cases has risen from 40 in 1940 to 54.7 in 1957-63 (Table III). Predominantly males have been affected: whereas the ratio of males to females was $12: 1$ in 1945 , it is now $4: 1$ (Table IV) and the incidence amongst females has remained virtually unaltered (Table I).

As some previous perforation surveys concerned themselves with both forms of peptic ulcer together, fewer figures for gastric and duodenal incidence separately are available. However, such figures as there are (Table I) suggest that the epidemic was confined to duodenal ulcers (Illingworth et al., 1944). The incidence for perforated gastric ulcer has not altered appreciably (Illingworth et al., 1944) (Table I).

\section{SUMMARY}

The incidence of perforated duodenal ulcer, $8 / 100,000$, and gastric ulcer, $2 / 100,000$, in Oxford and an area surrounding it, has been established by a retrospective examination of hospital in-patient notes and necropsy records.

Six cases where steriods may have provoked perforations are described.

An urban-rural difference, in which city dwellers had twice the perforation incidence of those in the surrounding country was found, supporting earlier findings at York (Pulvertaft, 1959).

ABO blood group figures for Glasgow, Aberdeen, York, and Oxford are given and it is suggested that the difference in the incidence of peptic ulcer in the north and south of the British Isles is in part a consequence of the variation in the ABO incidence.

The mean age, age-specific incidence, and fatality rate were calculated and were greater than in equivalent surveys performed in Aberdeen (Weir, 1960), Glasgow (Jamieson, 1955), and York (Pulvertaft, 1960) although the mortality rate was half that in Great Britain as a whole (Registrar General). The sex ratio was only $5: 1$, a low figure compared with previous survey results.
These findings were thought to support the idea that an epidemic of duodenal ulcers in males has occurred recently and is now passing away.

I am deeply indebted to Dr. E. D. Acheson for permission to use the facilities of the Oxford Record Linkage survey and for his constant encouragement and inspiration. Others who have given valuable help are Dr. J. GrimleyEvans and Mr. R. Goulding.

I am grateful to the surgeons at the Radcliffe Infirmary for permission to examine the case records of their patients.

Dr. Ada Kopec has kindly supplied figures on blood group variations obtained in the course of a nationwide survey.

\section{REFERENCES}

Acheson, E. D. (1964). The Oxford Record Linkage Study. A central file of morbidity and mentality records for a pilot population. Brit. J. prev. soc. Med., 18, 8-13.

Billington, B. P. (1960a). The Australian gastric ulcer change: further observations. Med. J. Aust., 2, 19-20.

(1960b). Gastric ulcer: Age, sex, and a curious retrogression. Aust. Ann. Med., 9, 111-121.

Clarke, C. A., Evans, D. A. P., McConnell, R. B., and Sheppard, P. M. (1959). Secretion of blood group antigens and peptic ulcer. Brit. med. J., 1, 603-607.

Howe, G. M. (1963). National Atlas of Disease Mortality in the United Kingdom. Nelson, London.

Illingworth, C. F. W., Scott, L. D. W., and Jamieson, R. A. (1944). Acute perforated peptic ulcer: frequency and incidence in the West of Scotland. Brit. med. J., 2, 617-620, 655-658.

Jamieson, R. (1955). Acute perforated peptic ulcer. Frequency and incidence in the West of Scotland. Ibid., 2, 222-227.

Jennings, D. (1940). Perforated peptic ulcer. Changes in age-incidence and sex-distribution in the last 150 years. Lancet, 1, 395398, 444-447.

Johnson, H. D. (1962). Peptic ulcer in hospital. Gut, 3, 106-117

Kopec, A. (1966). Personal communication.

Lazarus, S. (1964). Perforated peptic ulcer in Israel. Gut, 5, 590-596.

MacKay, C. (1966). Perforated peptic ulcer for the West of Scotland: a survey of 5,343 cases during 1954-63. Brit. med. J., 1, 701-705.

Pulvertaft, C. N. (1959). Peptic ulcer in town and country. Brit. J. prev. soc. Med., 13, 131-138.

Registrar General (1966). Statistical Review of England and Wales for 1964. H.M.S.O., London.

Segi, M., Fujisaku, S., and Kurihara, M. (1959). Mortality for gastric and duodenal ulcer in countries and its geographical correlation to mortality for gastric and intestinal cancer. Schweiz. Z.Path., 22, 777-784.

Susser, M., and Stein, Z. (1962). Civilization and peptic ulcer. Lancet, $1,115-119$.

Truelove, S. C. (1960). Stilboestrol, phenobarbitone and diet in chronic duodenal ulcer. Brit. med. J., 2, 559-566.

- , and Reynell, P. C. (1963). Diseases of the Digestive System, p. 170. Blackwell, Oxford.

Watkinson, G. (1958). The autopsy incidence of chronic peptic ulceration, a national and regional survey of 20,000 examinations performed in Leeds, England, between 1930 and 1949 and in nire towns in England and Scotland in 1956. Schweiz. Z. Path., 21, 405-432.

Weir, R. D. (1960). Perforated peptic ulcer in North-East Scotland. Scot. med. J., 5, 257-264. 